\title{
Penetrating Ocular Injuries in a Tertiary Health Facility
}

\author{
Kehinde Fasasi Monsudi ${ }^{1, *}$, Abdulkabir Ayansiji Ayanniyi ${ }^{2}$, Olasunkanmi Fatai Olatunji ${ }^{3}$, Isa AbdulFattah ${ }^{1}$ \\ ${ }^{1}$ Department of ophthalmology, Federal Medical Centre, Birnin Kebbi, Nigeria \\ ${ }^{2}$ Department of ophthalmology, College of Health Sciences, University of Abuja, Nigeria \\ ${ }^{3}$ Department of ophthalmology, University of Ilorin Teaching Hospital, Ilorin, Nigeria \\ *Corresponding author: kfmoshood@yahoo.com
}

Received April 25, 2013; Revised June 07, 2013; Accepted July 30, 2013

\begin{abstract}
Objective: To assess the pattern and aetiological factors for penetrating ocular injuries in a tertiary health facility. Materials and Methods: This was a retrospective review of all the cases records of penetrating eye injuries presenting to our eye unit over a period of 6 years. Results: There were 153 cases including 125 (81.7\%) males $28(18.3 \%)$ females with age range between 3 months and 85 years. Penetrating eye injury was common in children $0-16$ years $(42.5 \%)$ followed by adults' $\leq 30$ years $(41.6 \%)$. The commonest cause of penetrating ocular injuries was stick/wood (41.2\%). Injuries mostly occurred at home (65.4\%). Right eye only was involved in 58.2\% and both eyes were affected in $2 \%$. Overall visual outcome at last hospital visit showed $14 \%$ attained VA of 6/12 or better and $50 \%$ had visual acuities worse than 6/60. Poor visual outcome was associated with poor initial visual acuity $(\mathrm{p}=0.000)$. Conclusion: Injuries occurred more frequently on weekdays $(81 \%)$ than weekends. Following the ocular surgery, 3 patients developed endophthalmitis and 10 developed phthisis bulbi. Penetrating eye injury occurs mostly at home and mostly from stick/wood. Prevention of penetrating eye injuries requires parents, caregiver and children education on the danger of penetrating eye injury and improvement in home safety measure.
\end{abstract}

Keywords: road traffic accident, penetrating eye injury, stick/wood

Cite This Article: Kehinde Fasasi Monsudi, Abdulkabir Ayansiji Ayanniyi, Olasunkanmi Fatai Olatunji, and Isa AbdulFattah, "Penetrating Ocular Injuries in a Tertiary Health Facility." American Journal of Medical Sciences and Medicine 1, no. 4 (2013): 66-68. doi: 10.12691/ajmsm-1-4-4.

\section{Introduction}

Penetrating eye injury is the leading cause of visual impairment and visual loss worldwide. Various studies indicate a large preponderance of penetrating eye injuries among males $[1,2,3]$. The pattern of penetrating eye injury in African population differ from the developed countries. ${ }^{4}$ The causes of penetrating eye injury in adult is preventable while it is not in children because of their restless nature [4]. Thus worth investigating.

This study assessed the pattern and aetiological factors underlying penetrating eye injuries in patients, presented to only single tertiary referral hospital in Kebbi State, Nigeria serving a population of about 3.6 million.

\section{Methods}

All cases of penetrating eye injury presented to our eye unit over a period of 6 years, from $1^{\text {st }}$ January $2004-30^{\text {th }}$ December 2009 were identified by a medical record search. The following information was extracted from patient's folder; age, sex, day and time of injury, place of injury, cause, site and nature of injury, presented VA, final VA as at last hospital visit as recorded in folder, operation performed, and complication of surgery. Excluded are patients with partial thickness lacerations (lamella injury) ocular injury and patients who were initially repaired from other hospitals.

\section{Data Analysis and Statistical Method}

The data were double-entered and analyzed by SPSS16.0 software statistical package (2006 Statistical Package for the Social Sciences, Chicago, Illinois, USA).

Analysis was done using simple frequency proportions and chi square test for significance.

$\mathrm{P}<0.05$ was considered as statistically significant.

This study was approved by the Ethical Review Board of the Federal Medical Centre, Birnin Kebbi, Nigeria.

\section{Results}

Of the 153 patients, there were 125 (81.7\%) males and 28 (18.3\%) females with M: F 4.5:1 (SD 16) and age range of 3 months -85 years. Penetrating eye injury was common in children $0-16$ years $(42.5 \%)$, followed by adults $\leq 30$ years $(41.6 \%)$. Table 1 shows age and sex distribution of the patients. Follow up of the patients was for an average of 18 months. Right eye only was involved in $58.2 \%$ and both eyes were affected in 2 patients (1.3\%).

Penetrating ocular injury mostly occurred at home (65.4\%). Injuries at school were infrequent (4\%). Table 2 shows the causes of penetrating eye injury with 
stick/wood being the most common cause 63 (41.2\%).The highest number of penetrating eye injury occurred in 2009 with 47 cases. Table 3 shows the frequency of penetrating eye injury with year. Cornea was the mostly affected site of penetrating eye injury (28.8\%). The penetrating eye injury commonly occurred during morning hours (60.8\%) and during the weekdays (81\%). Most of our patients108 (70.6\%) applied topical eye medication purchased from the counter alone and 28 (18.3\%) patients applied both traditional and topical eye medication before presenting at our hospital. Most of the patients 137 (89.5\%) came to our facility 4 hours after the injury. At presentation to our hospital $87.6 \%$ had visual acuities of $6 / 18$ or worse.

Table 1. Age and Gender distribution of distribution of Patients

\begin{tabular}{|c|c|c|c|}
\hline \multirow{2}{*}{ Age (years) } & \multicolumn{2}{|c|}{ Gender } & \multirow{2}{*}{ Total } \\
\cline { 2 - 3 } & Male & Female & \\
\hline $0-9$ & 50 & 20 & 70 \\
\hline $10-19$ & 26 & 3 & 29 \\
\hline $20-29$ & 19 & 2 & 21 \\
\hline $30-49$ & 15 & 2 & 17 \\
\hline $40+$ & 15 & 1 & 16 \\
\hline Total & 125 & 28 & 153 \\
\hline
\end{tabular}

Table 2. Causes of penetrating eye injuries

\begin{tabular}{|c|c|c|}
\hline Causes of Penetrating Eye injury & Frequency & $\%$ \\
\hline Stick/wood & 63 & 41.2 \\
\hline Metal & 32 & 20.9 \\
\hline Stone & 12 & 7.8 \\
\hline Animal horn & 8 & 5.2 \\
\hline Knife & 7 & 4.6 \\
\hline Fist & 5 & 3.3 \\
\hline Broken Bottle & 4 & 2.6 \\
\hline Nail & 4 & 2.6 \\
\hline Bone & 3 & 2.0 \\
\hline Tyre explosion & 2 & 1.3 \\
\hline Gun shot & 2 & 1.3 \\
\hline Glass & 2 & 1.3 \\
\hline$*$ Others & 9 & 5.9 \\
\hline Total & 153 & 100 \\
\hline
\end{tabular}

*One (0.7\%) each of belt, knock out, dashboard, pen, seat, cutlass, axe, comb and road traffic injury

Table 3. Frequency of penetrating eye injury by year

\begin{tabular}{|c|c|c|}
\hline Year & Number & $\%$ \\
\hline 2004 & 19 & 12.4 \\
\hline 2005 & 10 & 6.5 \\
\hline 2006 & 21 & 13.7 \\
\hline 2007 & 27 & 17.7 \\
\hline 2008 & 29 & 19.0 \\
\hline 2009 & 47 & 30.7 \\
\hline Total & 153 & 100 \\
\hline
\end{tabular}

Overall visual outcome of the patients as at last hospital visit shows $14 \%$ attained VA of $6 / 12$ or better. However, $50 \%$ had visual acuities worse than 6/60. The presenting VA and final visual acuity of 45 patients and 41patients respectively cannot be determined because they were underage and uncooperative. However, light fixation and tracking of light were used in assessing the VA among the cooperative ones in this category of patients. The most performed operation following penetrating eye injury was suturing of corneo-scleral laceration 69 (45.1\%). Following the ocular surgery, 3 cases developed endophthalmitis and 10 developed phthisis bulb. No single of sympathetic ophthalmitis was reported. Six patients had primary evisceration due to severe irreparable penetrating eye injury. Most of the patients (93.5\%) were admitted at our unit for treatment and $79.1 \%$ of them spent 5 days at our facility before discharge.

\section{Disscusion}

The male/female ratio of $4.5: 1$ of our patients is in keeping with previous similar studies $[5,6,7,8,9]$. but slightly lower to what was reported by Wykes et al. [10] and Blomdal et al.[11] The difference may be due to the variety of ocular trauma evaluated in previous studies. The facts that males are more aggressive and adventurous in their behavior compare to females make them more prone to ocular trauma [6], furthermore because male children also exhibit aggressive behavior and violent outdoor activities compare to female children, these prone them more to ocular trauma. The majority (84.1\%) of individuals affected by penetrating eye injuries in our study are children and adults during an active age $(\leq 30$ years) this were similar to other studies $[6,9,12]$. Right eyes were mostly affected in our study (58.2\%) this is different from similar study by Fasina [9] who reported 45.9\% RE penetrating eye injuries, the reason for this difference may need to be elucidated through further study.. There were 2 cases of bilateral penetrating eye injury and all the two cases occurred in young adults of ages 25 and 30 years following local dane gun shot injuries. This highlighted the severity of multiple bullets out burst from local dane gun shot direct to the face.

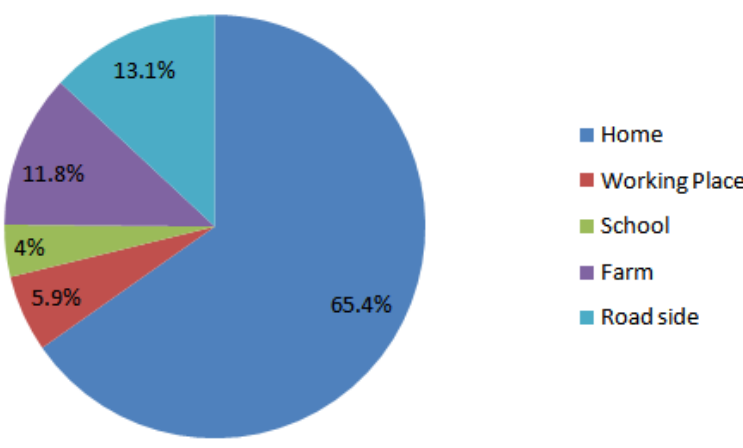

Figure 1. Place were penetrating eye injury occur

It is of note the majority of the injuries occurred at home $65.4 \%$ and is similar to previous study [9]. The lower number of penetrating eye injuries due to road traffic accident (RTA) may be due to enforcement of using seat belt by Federal road safety commission (FRSC), an agency responsible for the enforcement of road safety law. The reduction in perforating eye injuries from the introduction of compulsory seat belt legislation has been well documented [13] and it is a good example of preventive public health measure. Stick/wood used during play which were mistakenly poked in the eyes, were 
responsible for most of the ocular injury, and similar to previous study.14 Our observations, however, differ from those of Okoye6 and Fasina 9 who reported assault/combat and chip of metal or vegetative matter impacting the eye respectively to be the major cause of ocular injuries. The difference in observation between our study and previous studies 6, 9 emphasizes the variation in the causes of penetrating eye injury from locality to locality. In our study, penetrating eye injuries at school were infrequent (4\%), similar to Fasina9 who reported $5.9 \%$ of 135 cases from Ibadan. The reasons may be due to teachers' more supervision of school pupil at school than parents at home.

Cornea was the mostly affected site of penetrating eye injury (28.8\%). This is due to the fact that cornea is the most exposed part of the eye. The penetrating eye injury commonly occurred during morning hours (60.8\%) and during the weekdays (81\%). This might be due to more supervision of the children by the adult during the weekend compare to during the weekdays. Most of our patients (70.6\%) applied topical eye medication purchased from the counter before presenting at the hospital; this might have contributed to the poor visual outcome since the eyes were opened. More than two-thirds of the patients came to our facility 4 hours after the injury 137 (89.5\%) this is similar to previous studies who reported late hospital presentation following penetrating eye injury [9,14,15]. At presentation to our hospital, $12.4 \%$ had visual acuities of 6/12 or better. Overall final visual acuity of the last hospital visit of the patients shows $14 \%$ attained VA of $6 / 12$ or better. However, $50 \%$ had visual acuities worse than $6 / 60$. The final visual acuity of the patients in our study is similar to previous studies $[6,15,16]$. The most operation performed following penetrating eye injury were suturing of corneo-scleral laceration in 69 (45.1\%). Following the ocular surgery, 3 patients developed endophthalmitis and 10 developed phthisis bulb. Late hospital presentation, use of topical eye medication in an open eye and traditional eye medication might have contributed to this postoperative complication.

Limitation of the study is the retrospective nature however; our hospital is the only tertiary health institution and only hospital where all the cases of ocular injury in Kebbi State were being attended to as at the time of this study. Thus the study is representative of penetrating eye injuries in the state.

\section{Conclusion}

Penetrating eye injury occurs mostly at home and mostly from stick/wood. Prevention of penetrating eye injuries requires parents, caregiver and children education on the danger of penetrating eye injury and improvement in home safety measure.

\section{References}

[1] Schein OD, Hibberd PL, Shingleton BJ, Kunzweiler T, Frambach DA, Seddon JM, Fontan NL, Vinger PF. The spectrum and burden of ocular injury. Ophthalmology 1988; 95(3): 300-5.

[2] MacEwen CJ. Eye injuries: a prospective survey of 5671 cases. Br J Ophthalmol 1989; 73(11): 888-94.

[3] Katz J, Teilsch JM. Lifetime prevalence of ocular injuries from the Baltimore Eye Survey. Arch Ophthalmol 1993; 111(11): 1564-8.

[4] Grieshaber MC, Stegmann R. Penetrating eye injuries in South African children: aetiology and visual outcome. Eye 2006; 20:789795.

[5] Canavan YM, O'Flaherty MJ, Archer DB, Elwood JH. A 10- year survey of eye injuries in Northern Ireland. Br J Ophthalmol 1980; 64: 618-25.

[6] Okoye OI. Eye injury requiring hospitalisation in Enugu Nigeria: A one-year survey. Niger J Surg Res. 2006; 8:34-7.

[7] Cillino S, Casuccio A, Di Pace F, Pillitteri F, Cillino G. A fiveyear retrospective study of the epidemiological characteristics and visual outcomes of patients hospitalized for ocular trauma in a Mediterranean area. BMC Ophthalmol. 2008; 8: 6-14.

[8] Soliman MM, Macky TA. Pattern of ocular trauma in Egypt. Graefes Arch Clin Exp Ophthalmol. 2008; 246: 205-12.

[9] Fasina O. Epidemiology of Penetrating Eye Injury in Ibadan: A 10-Year Hospital-Based Review. Middle East Afr J Ophthalmol. 2011 Apr-Jun; 18(2): 159-163.

[10] Wykes WN. A 10-year survey of penetrating eye injuries in Gwent. Br J Ophthalmol 1988; 72: 607-611.

[11] Blomdahl S, Norell S. Perforating eye injury in the Stockholm population: an epidemiological study. Acta Ophthalmol 1984; 62/3: 378-90.

[12] Bekibele CO, Ajayi BG, Baiyeroju AM, Ayeni EA. Visual outcome of pressurised bottled drinks related eye injuries in Ibadan. Afr J Med Sci. 2003; 32: 85-8.

[13] Hall NF, Denning AM, Elkington AR, et al. The eye and the seatbelt in Wessex. Br J Ophthalmol 1985; 69:317-9.

[14] Michael I, Moses C, Michael B Ocular injuries in Malawi Br J Ophthalmol. 1982; 66:145-148

[15] Baiyeroju-Agbeja AM, Olurin-Aina OI. Penetrating eye injuries in children in Ibadan. Afr J Med Med Sci. 1998; 27:13-5.

[16] Niiranen M, Raivio I. Eye injuries in children. Br J Ophthalmol. 1981; 65: 436-8. 